\title{
Environmental Analysis for All: The Need for Cheap Analytical Methods
}

\section{Neil Fitzgerald"}

Department of Chemistry, School of Science, Marist College, NY, USA

*Corresponding author: Neil Fitzgerald, Assistant Dean of Science and Associate Professor of Chemistry, Acting Chair of Anthropology, School of Science, Marist College, 3399 North Road, Poughkeepsie, NY, USA, Tel: 845 575-3000 ext. 2491; E-mail: Neil.Fitzgerald@marist.edu

Rec date: Apr 10 2014; Acc date: Apr 14 2014; Pub date: Apr 162014

Copyright: @ 2014 Fitzgerald N. This is an open-access article distributed under the terms of the Creative Commons Attribution License, which permits unrestricted use, distribution, and reproduction in any medium, provided the original author and source are credited.

\section{Analytical Methods}

I recently attended PITTCON, the largest laboratory science conference and exposition in the world, held in Chicago. For someone with a background in instrumental analytical chemistry the rows of gleaming, high-tech analytical instruments were intoxicating. I was a kid in a candy store. But I was also reminded that PITTCON was the venue of a pivotal experience in my professional career. Almost exactly five years prior I was in the same conference center listening to a keynote speech given by Dr. George Whitesides. Throughout the lecture, the distinguished Harvard professor bestowed the virtues of low cost analytical methods with a particular emphasis on providing medical diagnostics to the developing world. In fact he stated that in his opinion it is the responsibility of the developed world to do so. It may not have been a message that many in the audience wanted to hear but I agree wholeheartedly.

Professor Whitesides was referring primarily to healthcare applications but the philosophy equally applies to environmental analysis. Indeed the environment and human health are inextricably linked. People have a right to know if water is good to drink, food fit to eat and air safe to breathe in order to protect the health of themselves, their friends and families. A goal that cannot be achieved on a large scale through development of increasingly complex and expensive laboratory instruments. Two of the most promising approaches to the development of low cost analytical methods in my opinion are microfluidic paper-based analytical devices ( $\mu$ PADs) and nanoparticle based colorimetric methods. Both offer possibilities for cheap and simple analytical tests. $\mu$ PADs are simple devices printed on cheap paper substrates which use capillary action to avoid the need for external pumps and can be easily and safely disposed of by burning [1]. Functionalized nanoparticles have been an area of substantial research efforts recently. Gold and silver nanoparticles interact with visible light. Aggregation of these particles causes an observable color change. Functionalized nanoparticles can be designed to be selective and sensitive. While my research career began by seeking improvements in methods of inorganic analysis using some high cost equipment including ICPMS and laboratory microwave systems, I have always had an interest in developing cheaper and/greener methods for environmental analysis. For example, we have recently begun to investigate low cost visible spectrometers. For less than $\$ 10$ a spectrometer can be constructed using a computer web cam or cell phone camera as the detector. Such simple devices might be used to measure environmental samples. On my visits to the West African country of Ghana, cellphone usage was ubiquitous which demonstrated to me a huge potential for cell phone based methods. This fact that hasn't escaped Professor Whitesides [2].
Environmental monitoring is essential but typically expensive and generally difficult to fund. This was demonstrated to me after Hurricane Sandy made landfall in the New York City area. Following the storm precious little funding was made available to study potential chemical contamination in flooded regions. Our approach, suggested by Dr. Spodek-Keimowitz at Vassar College, was to ask the public to mail soil samples to us for analysis. We scraped together funds from our respective institutions and turned to crowd funding to make up the shortfall. It may not be the ideal monitoring strategy but it allowed us to be one of the few (if not only) groups to perform a significant survey of soils immediately after the flood waters had receded. When the measurements were complete another difficulty arose. How were we to interpret the results given the limited data available from the New York metropolitan area prior to the storm? The British Geological Survey recently reported the completion of a forty year project to map elemental concentrations over the entire British Isles [3]. How useful similar data would have been to us if it had been available for the New York City area. Perhaps citizen science projects using low cost analytical methods are the answer to provide chemical mapping of large areas.

Another field close to my heart is chemical education. The advantages of low cost instrumentation in the high school or college settings are clear. Principles of chromatography, spectroscopy, and electrochemistry can be taught to all economic abilities with a little ingenuity on our part. Research experiences based on environmental analysis could be made accessible to students of all levels and backgrounds and are perhaps the most educationally effective and rewarding experiences that we can offer.

Of course improvements in traditional laboratory methods will continue to be important but it is my hope that some of the papers in this journal will highlight low cost methods for environmental analysis with applications to ensuring healthy living conditions for all, increasing the monitoring of our environment, and improving the educational experiences of our students.

\section{References}

1. Martinez AW, Phillips ST, Whitesides GM, Carrilho E (2010) Diagnostics for the developing world: microfluidic paper-based analytical devices. Anal Che 82: 3-10.

2. Martinez AW, Phillips ST, Carrilho E, Thomas SW 3rd, Sindi H, et al. (2008) Simple telemedicine for developing regions: camera phones and paper-based microfluidic devices for real-time, off-site diagnosis. Anal Chem 80: 3699-3707.

3. BBC News (2013) Map traces UK's elemental signature. 